\title{
Storytelling, una estrategia para un aprendizaje significativo mediante la comunicación tecnológica.
}

\author{
Storytelling, a strategy for a meaningful learning through technological communication. \\ Claudia Gil-de la Piedra ${ }^{a}$
}

\begin{abstract}
:
Due to the quick progress of technology and the globalization process, nowadays, there are new possibilities of communication through cyberspace and, consequently, foreign language learning has become increasingly important. Nevertheless, it is necessary to come up with innovative strategies for the teaching and learning processes. This includes the new technologies to enable the design of alternative projects, which focus on meaningful and long lasting learning. This paper proposes Storytelling as a ludic way of agglutinating previous and new knowledge, making use of different IT tools such as Flipgrid and Powtoon. Storytelling encourages the identification and retention of concepts and stimulates students so that they share ideas and develop their critical thinking. This work highlights the importance of empathy and human relationships and proposes a new way to collaborate with technology, without replacing human intellect and subjectivity by the former ones, in order to achieve a rewarding experience of meaningful learning.
\end{abstract}

\section{Keywords:}

Empathy, meaningful learning, sharing, Storytelling, teaching-learning processes, technology

\section{Resumen:}

Debido al rápido avance de la tecnología y al proceso de globalización, existen actualmente nuevos horizontes de comunicación dentro del nuevo espacio cibernético y, en consecuencia, el aprendizaje de lenguas extranjeras se ha vuelto cada vez más importante. Sin embargo, es necesario reformular las estrategias de los procesos de enseñanza-aprendizaje, asimilando las nuevas tecnologías para poder diseñar proyectos alternativos que se enfoquen en un aprendizaje significativo y duradero. Este trabajo propone el Storytelling o la narración de historias como una manera lúdica de ensamblar conocimientos previos y nuevos, valiéndose de diferentes herramientas tecnológicas como Flipgrid y Powtoon. La narración favorece la identificación y retención de conceptos y estimula el intercambio de ideas, así como el pensamiento crítico. Este trabajo pone en relieve la importancia de la empatía y las relaciones humanas y propone una manera de colaborar con los medios tecnológicos, sin ser estos el remplazo del intelecto y la subjetividad humanos, para lograr una experiencia enriquecedora de aprendizaje significativo.

\section{Palabras Clave:}

Aprendizaje significativo, empatía, intercambio, procesos de enseñanza-aprendizaje, Storytelling, tecnología

\section{INTRODUCCIÓN}

Para comenzar este artículo es necesario dejar claro qué es Storytelling. A veces, se llega a pensar que es algo complejo, novedoso y complicado, pero no. El Storytelling no es una aplicación nueva ni depende de la tecnología; muy al contrario, su significado es muy simple y se refiere a la acción de contar historias. A todos nos gustan las historias y éstas ponen en evidencia la intimidad del ser humano, su subjetividad, su cultura y su cosmovisión.

Existen muchísimas formas de contar una historia; existen historias de amor, de guerra, de familia, etc., y se pueden contar de muchas maneras. Lo cierto es que todos vivimos dentro de una historia que se relaciona con otras historias de

${ }^{a}$ Corresponding author, Instituto Tecnológico de Estudios Superiores de Monterrey, https://orcid.org/0000-0001-6916-081X, Email: dickens.1789@gmail.com 
las personas que nos rodean. De este modo, y a partir de nuestra experiencia individual, es posible establecer un diálogo con el exterior. Es imposible prescindir de la narración porque esa es la forma en que nos vinculamos con los demás. Esto no quiere decir que el Storytelling no tenga ninguna complejidad, sino que requiere poner de manifiesto nuestro sentir para entrar en relación con otros.

Otra manera de relacionarse es mediante el aprendizaje lingüístico. Aprender una nueva lengua es una manera de aprender a intercambiar historias que nos cuentan las costumbres y tradiciones de una civilización o cultura distinta de la nuestra. La historia puede ser contada a través de imágenes, canciones, símbolos o sencillamente mediante el habla, que es el modo más común. Sin embargo, las otras formas de relato ponen en relación el significante y el significado apelando a su relación con el ejercicio de memorización y asimilación.

Este trabajo tiene como objetivo principal mostrar algunas maneras de contar historias para aprender una lengua extranjera, valiéndose de diferentes herramientas tecnológicas y aplicaciones. A través de los ejemplos citados en este artículo, se pretende demostrar que los relatos, en sí mismos, implican el desarrollo de diversas competencias, lingüísticas y sociales, y que, al mismo tiempo, ponen en marcha una serie de relaciones entre el aprendiente y su medio que le permiten reconstruir el mundo a partir de una nueva visión. Por lo tanto, el alumno habrá adquirido un aprendizaje significativo en vez de simple memorización y fuera del contexto de la mera simulación. Asimismo, se pretende poner en relación al aprendiente, al enseñante y su entorno mediante un ejercicio pragmático que conlleva una experiencia significativa académica y emocionalmente.

La tecnología ha puesto a nuestra disposición nuevos lenguajes y medios eficaces para comunicarnos. Si bien la tecnología no puede sustituir al lenguaje, si puede enriquecerlo, proporcionándole nuevas herramientas que estimulen la creatividad y la imaginación. Al mismo tiempo, los mensajes pueden tener mayor alcance, pues las imágenes, los símbolos y los colores usados tienen un mayor impacto en el inconsciente. El uso de la tecnología puede ser controversial entre los docentes según su formación, no obstante, es ya una parte inherente de nuestra realidad y es preciso utilizarla de tal manera que pueda aportarnos nuevas estrategias de comunicación sin remplazar el entendimiento ni la subjetividad.

El alcance de las historias que una persona es capaz de contar puede extenderse en clase y puede motivar a los alumnos a conocer mejor su entorno, desde la historia propia, donde existe un reconocimiento de la identidad cultural, hasta la percepción y el encuentro con otras culturas que ofrecen una perspectiva alterna. Al mismo tiempo, si estos relatos se vinculan con la Historia, este ejercicio permite la praxis de la lengua en un contexto real que da inicio a la transición para hacer a un lado la simulación del jeu de rôle y empezar la comprensión y análisis del mundo académico y de investigación.

\section{UN APRENDIZAJE COMPLETO}

Por lo general, sabemos desde hace unas décadas que los métodos de enseñanza han ganado importancia en el mundo teórico y académico y han intentado reformular estrategias para mejorar el aprendizaje y volverlo más efectivo. No obstante, en muchos lugares de América Latina aún no parece quedar claro qué significa "efectivo" o "significativo". Este trabajo está centrado en la enseñanza de lenguas extranjeras; sin embargo, tiende a establecer relaciones interdisciplinarias y, al mismo tiempo, el Storytelling puede servir para alumnos de cualquier edad y cualquier nivel, ya que el lenguaje es parte inherente del ser humano, así como el discurso es constructor de significado y, en consecuencia, de ideologías. Lo único que puede variar es el nivel de complejidad de la estructura lingüística.

Es importante señalar que el objetivo de contar historias en clase es promover la ilación de ideas y el intercambio de las mismas. Aunque cabe hacer notar que existe un mayor privilegio en esta estrategia y es el placer que nos provoca contar historias. Esta práctica no es en absoluto similar a la discusión académica, la cual fue definida por David Cooper (1990) como "un procedimiento interactivo, a partir del cual profesor y alumnos hablan sobre un tema determinado" ( $p$. 114). Existe ya un largo camino entre David Cooper y nuestra época; nos hemos dado cuenta ya de la importancia de interactuar y del intercambio gracias a la globalización. Igualmente, nos hemos dado cuenta de la relevancia de la relación enseñante-aprendiente, aunque aún es difícil establecerla. A diferencia de una discusión, contar una historia no es el simple hecho de establecer una relación académica, sino de experimentar un contacto placentero en el aula. Las historias provocan en nosotros sensaciones, emociones e imágenes, las cuales nos ayudan a relacionar un concepto con su equivalente, relación de significante y significado, en un ejercicio pragmático y lúdico. La sensación de bienestar es más importante de lo que se ha creído hasta ahora y ésta aumenta cuando el aprendizaje tiene una relación con nosotros o con lo que nos provoca curiosidad. No se trata de entablar amistad con los alumnos, sino de establecer una relación de afecto mutuo hacia el conocimiento.

Frida Díaz Barriga (1993) había señalado que "uno de los reproches más fuertes que se le han hecho a la evaluación tradicional es que se ha preocupado por evaluar saberes descontextualizados por medio de situaciones artificiales" ( $p$. 364). A pesar de que han pasado casi tres décadas, esta situación parece seguir representando un reto para los docentes. Por esta razón, la ficción se presenta como un medio alternativo de construir nuevas realidades a través de un ejercicio creativo donde es posible otorgar significado a un hecho específico a partir de diversas perspectivas.

$\mathrm{Si}$ bien el Storytelling no es una actividad evaluativa, es posible considerarla como una tarea integradora que engloba diferentes tipos de conocimiento. En el caso del aprendizaje de lenguas extranjeras, el Storytelling permite al alumno la práctica de la lectura, durante la cual buscará información, leerá con otros compañeros o individualmente, buscará fuentes y podrá organizar datos. Posteriormente, podrá reformular la historia, ponerla en relación con otras historias, compararla con su entorno y retransmitir una nueva interpretación. Dicha reinterpretación puede ser primero escrita, para estimular la producción y dar estructura a un discurso. Finalmente, la producción oral se lleva a cabo en el hecho de "contar". Cabe enfatizar que esta acción resulta mucho más fácil en un ambiente lúdico donde el alumno adquiere mayor confianza 
para expresarse y contar algo que le interesa y le provoca entusiasmo. En cuanto a la evaluación, esta actividad resulta muy productiva, pues las rúbricas pueden ajustarse en función del nivel de producción oral y escrita que se pretende evaluar dentro del aula y, al mismo tiempo, el alumno se prepara para una evaluación oficial, examen de certificación, etc.

Independientemente de la rúbrica de evaluación, el Storytelling favorece en gran medida la creación de un discurso. No hay que olvidar que los niños pequeños empiezan su experiencia de comunicación con cuentos e historias fantásticas. El Storytelling permite a los docentes visibilizar la verdadera comprensión de un tema. El alumno puede imaginar una historia a partir de nuevo vocabulario y, a su vez, estructurarlo en un texto coherente. Al mismo tiempo, el alumno carga de significado su historia y da evidencia de su comprensión global sobre el tema. Así es como el enseñante puede medir el conocimiento significativo sin basarse únicamente en la evaluación cuantitativa. Grant Wiggings y Jay McTigh (2008) hacen hincapié en que "getting evidence of understanding means crafting assessments to evoke transferability" " (p. 48). Por lo tanto, la evaluación debe desmarcarse del concepto rígido de examen y rúbrica. Como se ha mencionado, la retransmisión del aprendizaje es una evidencia concreta y definitiva de la comprensión de lo aprendido. No sólo es una tarea del enseñante diseñar una consigna creativa para enseñar, sino permitir a sus aprendientes el diseño creativo de su propio conocimiento.

Según Wiggings y McTigh (2008), el estudiante que ha asimilado realmente su aprendizaje es capaz de explicar, interpretar, aplicar, tomar perspectiva, empatizar y finalmente, llegar a un nivel metacognitivo que le dé conocimiento de sí mismo. Este proceso representa un aprendizaje encaminado a una realización personal y a un nivel de funcionalidad en la sociedad, trascendiendo el nivel puramente académico. Por esta razón, es fundamental que el proceso de enseñanzaaprendizaje relacione al individuo con su entorno y con sus semejantes. En este caso, el aprendizaje lingüístico nos conecta con la cultura implícita en la lengua y conlleva la toma de conciencia de otras tradiciones y de la propia identidad. En consecuencia, el aprendizaje lingüístico establece un lazo de gran importancia con otras disciplinas como la historia, la literatura y las artes, las cuales amplían la visión del mundo y permiten una toma de conciencia social. Sin embargo, nuestra época presenta grandes cambios y una nueva disciplina que emerge con gran rapidez es el desarrollo de la comunicación tecnológica.

La tecnología representa una búsqueda de nuevos lenguajes puesto que ha venido a cambiar la forma en que percibíamos la realidad. Durante mucho tiempo, la tecnología ha tenido una perspectiva ambivalente. Por un lado, se ve con simpatía pues se considera una señal de progreso y una manera de facilitarse el trabajo. Por otra parte, la tecnología se ha señalado como el remplazo de la inteligencia humana y como un medio de evadir el trabajo y el contacto con otros, como había denunciado Zygmunt Bauman (2011) a principios de nuestro siglo, afirmando que vivimos en una sociedad donde "las redes remplazan a las estructuras, en tanto que un juego ininterrumpido de conexión y desconexión de esas redes, así como la interminable secuencia de conexiones y desconexiones, remplazan a la determinación, la fidelidad y la

\footnotetext{
* Obtener evidencia del entendimiento significa el arte diseñar tareas para evocar la capacidad de transferir. (Traducción mía)
}

pertenencia" (p. 19). Sin embargo, es menester llegar a un punto medio ya que la tecnología ha aportado diversas herramientas y ha transformado el mundo en el que vivimos. Por lo tanto, es imperativo no perder de vista que la tecnología no es el remplazo del lenguaje, sino una herramienta para recrear el lenguaje.

La tecnología no necesariamente significa la pérdida de las habilidades de lecto-escritura; significa más bien un reto sobre cómo aprender a usar estas nuevas plataformas y diseñar actividades complejas que desafíen a los estudiantes, forzándolos a dar su mejor versión. Desde mis primeros estudios en el campo de la enseñanza interdisciplinaria de lenguas extranjeras tenía claro que la lectura es fundamental para el diseño y desarrollo de una clase pues "a través de esta práctica, el alumno aplica diversas competencias tales como la comprensión global, la comprensión detallada, la asociación precisa entre pregunta y respuesta y la identificación de conceptos clave" (Gil de la Piedra, 2014, p. 21). Esto también quiere decir que no sólo es necesario tener en cuenta el contenido, sino la capacidad de crear, de reflexionar y de ser capaces de interactuar con otros en un contexto que no sea meramente de simulación.

Del mismo modo, se han retomado varias propuestas de diseño curricular enfocadas en la narración de historias: "A good story both enlightens and engages; it helps us remember and connect. A clear and compelling narrative can help us find meaning in what may have previously seemed to be abstract or irrelevant ${ }^{\dagger}$ " (Wiggings y McTigh, 2008, p. 89). La narración de historias apela al lenguaje en todo su esplendor, ya que permite utilizar elementos de vocabulario, dar estructura a las categorías gramaticales, hilar ideas y estructurar discursos; además de aprender a narrar, cuestionar y argumentar, lo cual es parte fundamental del aprendizaje, como señalaron Wiggings y McTigh (2008), "Understanding involves matching our ideas, knowledge and actions to context" (p. 93). Actualmente, la comunicación resurge a partir de las plataformas virtuales, pues éstas nos permiten usar todo tipo de lenguajes: símbolos, imágenes, sonidos, letras, etc., proporcionando recursos suficientes y favoreciendo un aprendizaje placentero y disfrutable.

Es necesario contraponer este argumento con la mercantilización de la educación. Desde principios del siglo XX, críticos como Paul Valéry habían señalado la educación como un producto mercantil, "le but de l'enseignement n'étant plus la formation de l'esprit, mais, l'acquisition du diplôme, c'est le mínimum exigible qui devient l'objectif des études (...) Le diplôme donne à la société un fantôme de garantie ${ }^{\S \text { " }}$ (Valéry, 2011, p. 11). Esta idea, retomada por Zygmunt Bauman (2013), quien explica que en la actualidad la educación ya no es vista como un proceso, sino como un producto, pone en relieve la necesidad de replantear los objetivos de enseñanza y fomentar en los alumnos el deseo de conocer y de experimentar.

\footnotetext{
† Una buena historia ilustra y al mismo tiempo compromete; nos ayuda a recordar y a conectar. Una narrativa clara y convincente puede ayudarnos a encontrar significado en lo que previamente pareciera abstracto o irrelevante. (Traducción es mía)

\$ El entendimiento involucra relacionar nuestras ideas, conocimientos y acciones para contextualizar. (Traducción mía)

${ }^{\S}$ El objetivo de la enseñanza ya no es la formación del espíritu sino la adquisición del diploma, es el mínimo exigible que se convierte en el objetivo de los estudios (...) El diploma da a la sociedad una ilusión de garantía. (Traducción mía)
} 


\section{TECNOLOGÍA COMO UN LENGUAJE ALTERNATIVO Y UNA HERRAMIENTA DE APRENDIZAJE}

La tecnología ofrece actualmente diversas aplicaciones para diseñar imágenes, videos, audios, podcast, los cuales no son únicamente un medio innovador de comunicar, sino que representan un nuevo lenguaje para expresar ideas, sentimientos y, por supuesto, conocimientos teóricos. Como ya han señalado investigadores como Naomi Alderman (2015), la convergencia digital modificó y expandió las formas de narrar, especialmente en cuanto al tipo y nivel de participación que podía tener el usuario; Alderman afirma que los videojuegos son uno de los mejores dispositivos para contar historias. Las imágenes pueden volver más ameno el desarrollo de una generalización; asimismo, sirven como apoyo para hacer una problemática o un planteamiento más explícito. Sin embargo, es necesario enfatizar que no podemos remplazar el conocimiento mediante la tecnología y que ésta no remplaza el pensamiento humano. Un ejemplo de esto son los diccionarios y traductores electrónicos que, en un momento dado, pueden resolver una necesidad de comunicación inmediata. No obstante, éstos no pueden estructurar una idea, ni desarrollar un concepto, incluso a veces ni siquiera distinguir un complemento de objeto directo de un complemento circunstancial.

La importancia de las lenguas extranjeras reside precisamente en la capacidad que proporciona a quien las emplea de pensar críticamente de una manera empática hacia su entorno y hacia quienes son diferentes a éste, así como de estructurar coherentemente un discurso. Una lengua extranjera desarrolla la empatía a través del entendimiento de lo ajeno y la comprensión de una cosmovisión distinta de la nuestra. Es posible establecer fácilmente una equivalencia lingüística, pero culturalmente no es tan fácil como parece. Por esta razón, la tecnología se presenta como una aliada que nos permite buscar un modo de aprender alternativo, más integral, valiéndose de diversos lenguajes y abriendo un diálogo intercultural dentro del espacio cibernético. El diálogo, tan necesario en nuestro mundo contemporáneo, se establece desde el primer acercamiento con otras culturas y personas de otros países, explorando la historia, el arte y la vida cotidiana de sociedades diferentes. La tecnología nos proporciona un medio de exploración y, al mismo tiempo, de comunicación. Sin embargo, cabe resaltar la importancia de ésta en la construcción y asimilación de la propia historia y la identidad individual.

Todos los días, millones de personas cuentan una historia; cuentan lo que les ha sucedido durante el día, lo que han hecho en el trabajo o en la escuela, a quien han conocido, lo que han comido y lo que han visto en internet. La acción de contar historias está muy arraigada y parece incluso inherente a la naturaleza humana. Gracias a las historias que nos cuentan podemos conocer lo desconocido, aprender comportamientos nuevos, conocer personas e incitar nuestra curiosidad. Las historias también nos construyen y delimitan la identidad individual y colectiva; pueden ir desde una autobiografía hasta la "historia universal" o nacional. Aunque no hay que olvidar que de un mismo hecho parten muchas historias que se cuentan de manera diferente; así que contar historias no sólo nos permite describir un hecho, sino escuchar diferentes perspectivas.

Esto último tiene crucial importancia debido a que, como han señalado algunos teóricos de los estudios culturales como Mabel Moraña (2014), vivimos en una época en la que existen "nuevas formas de subjetividad marcadas por múltiples hibridaciones" (p. 179). La globalización ha vuelto visibles las culturas heterogéneas abriendo nuevos panoramas y en consecuencia, surge la posibilidad de compartir e intercambiar culturas y tradiciones. Del mismo modo, Moraña (2014) señala la necesidad de pluralizar la concepción del sujeto y sus modalidades de intervención simbólica. En este caso, la tecnología nos permite concebir nuevas formas de diálogo dentro de un espacio cibernético que abre el espectro de comunicación. Es pertinente cuestionar el alcance de los medios tecnológicos para vincular distintas realidades $\mathrm{y}$, asimismo, su capacidad para pluralizar nuestra concepción del mundo y de otros ciudadanos del mundo.

Si vinculamos la narración de historias con la tecnología, tendremos como resultado una práctica cotidiana en un espacio abierto para la discusión y el intercambio de ideas, de fácil acceso y fácil difusión. Ante la imperativa necesidad de vincularnos con otros mundos en el ámbito empresarial, educativo y científico, no debemos olvidar la vinculación de nuestra subjetividad y de la propia identidad. En la actualidad, millones de personas construyen su identidad a través de una historia dentro del ciberespacio, lo cual se puede observar todos los días en las redes sociales. Por esta razón, el Storytelling resulta una alternativa simple y cotidiana que puede manejarse en varios niveles lingüísticos y en diferentes contextos, ya que la gente, por lo general, está acostumbrada a esta práctica, tanto en la lengua escrita como en la oralidad.

El Storytelling consiste en estudiar un objeto o suceso que puede enlistar emociones en una narración y es utilizado para nombrar las estructuras o los campos que captan en el momento justo y preciso la atención de un auditorio (Porcher y Groux, 2013). El Storytelling nos permite abordar temas muy diversos, plantear problemáticas, metaforizar problemas e incluso producir un acercamiento subjetivo de los estudiantes hacia las prácticas culturales de lectura y apreciación del arte. $\mathrm{Si}$ fomentamos esta práctica en la enseñanza de lenguas extranjeras, estaremos igualmente acercando a los aprendientes a la dimensión cultural de la lengua estudiada. En adición, es posible narrar historias de varios orígenes y establecer, en niveles más avanzados, un diálogo intercultural que muestre similitudes y diferencias entre la cultura de origen y aquella que es objeto de estudio.

En torno a este trabajo teórico, James M. Turner (1998) afirma que la narratología se ha constituido un campo de estudio interdisciplinario nutrido por investigaciones tanto teóricas como experimentales que engloban las teorías literarias y cinematográficas, los estudios críticos y la retórica. Dentro de esta dinámica, el profesor está obligado a animar, motivar y promover el interés de los estudiantes en la historia contada, convirtiéndose así en Storyteller. No obstante, este trabajo propone retomar la propuesta incluyendo a los alumnos como Storytellers y, de este modo, impulsar la producción oral en la lengua que se está enseñando.

El plagio es sin duda una constante preocupación para los docentes y, antes de presentar los ejemplos, es pertinente señalar que la práctica del Storytelling debe ligarse con las experiencias de los alumnos y con su punto de vista pues, de este modo, los enseñantes podrán motivar la creatividad y 
reducir la posibilidad de plagio. Es preciso hacer notar que el alumno puede contar cualquier historia, puede recuperarla del ciberespacio, de algún libro de cuentos o de alguna película, pero la importancia del ejercicio reside en cómo contarla, desde su visión y punto de vista. Dado que nadie puede pensar del mismo modo que otra persona, el alumno se ve obligado a reformular la historia en función de su capacidad lingüística y la comprensión que tiene del texto consultado. En los ejemplos posteriores, la historia se desconstruye y se reformula a través de hipótesis, de finales alternativos y la búsqueda de nuevas perspectivas. El docente puede estimular a los alumnos con preguntas, de modo que éstos se vean en la necesidad de exponer y no de repetir. Igualmente, en el caso de la producción escrita, el docente puede establecer algunas preguntas y lineamientos que estén basados en la vivencia o en el punto de vista del estudiante; por ejemplo, justificar la elección del tema, cuál es, según su opinión, la idea principal del texto o por qué es relevante rescatar esta historia. Aunado a esto, el docente puede delimitar más la consigna, pidiendo el uso de vocabulario específico y estructuras gramaticales concretas. De este modo, es posible que los alumnos cuenten una misma historia pero, difícilmente, lo harán de la misma manera.

A continuación, se muestran evidencias y propuestas de la utilización del Storytelling, utilizando la tecnología, en diferentes aplicaciones como flipgrid.com, www.canva.com y powtoon.com, en las cuales, utilizando distintos lenguajes como imágenes, video, texto y collage, es posible crear un espacio lúdico de aprendizaje que proporcione una comprensión real y significativa, así como un acercamiento a nuevas identidades y que permite abordar conceptos que marcan nuestra realidad y relacionarlos entre sí.

\section{LA NARRATIVA DENTRO DEL CIBERESPACIO: UN \\ AULA VIRTUAL}

Existen diversas aplicaciones que pueden utilizarse para contar una historia. Dicha diversidad no corresponde a la innovación tecnológica, sino a la amplitud del lenguaje en sí mismo, pues podemos apelar al lenguaje de señas, lenguaje musical, expresiones artísticas, oral, escrito, visual, híbrido y, por supuesto, a la diversidad lingüística. Henry Jenkins (2006) afirma que en la narrativa comercial han proliferado las narrativas transmedia, utilizando diversos medios como la película, el videojuego, o las series Web. A continuación, presentamos algunos ejemplos del uso de las aplicaciones en clase de lengua extranjera.

\section{Canva: Infografías y diseño artístico}

Canva, https://www.canva.com/es_es/, es una aplicación que proporciona recursos de diseño gráfico. Canva ofrece colores, imágenes y diseños de figuras que pueden ocuparse para crear infografías, posters y secuencias de imágenes que permiten vincular frases cortas, conceptos e incluso armar párrafos completos de ideas principales, vincularlos con imágenes y contar una historia. Esta aplicación puede servir para niveles básicos, ya que la asociación entre imagen y palabra es mucho más sencilla apelando a los colores y formas que el mismo alumno carga de significado.
Canva puede usarse para crear una historieta y una pequeña narrativa gráfica. Aunque, en niveles intermedios puede funcionar como un medio interactivo para la síntesis de ideas principales. Canva es un lienzo donde se puede contar una historia de ficción, o también la historia de la tradición cultural. En un curso de francés de nivel intermedio, impartido por mí en el Instituto Tecnológico de Monterrey, campus Ciudad de México*, Canva sirvió para contar a otros acerca de una región o país francófono, sus costumbres y tradiciones. Algunos estudiantes decidieron contar historias de hechos que marcaron dichas regiones, del origen de la francofonía dentro de esa región o de ciertas costumbres locales como danzas y funerales. Canva permitió que los alumnos hicieran posters e infografías para apoyar una exposición oral en la que contaban a otros miembros del grupo sobre los lugares que habían conocido a través de sus investigaciones a partir de la búsqueda de información sobre un país o región de su elección donde se hablara francés (Figura 1).

Cabe resaltar que esta actividad no sólo fomentó la comprensión escrita y la producción oral, sino que enfatizó la diversidad de los países relacionados con la lengua francesa, sus costumbres, tradiciones y, asimismo, puso en relieve la heterogeneidad lingüística al mostrar las diferencias lexicales y fonéticas de un país a otro. Actualmente, la diferencia constituye una nueva categoría imprescindible en nuestro entendimiento ya que el aprendizaje tiende a la empatía, al reconocimiento de la alteridad y, a través de esto, el conocimiento de sí mismo (metacognición). Asimismo, Mabel Moraña (2014) señala que, "como respuesta a los desafíos impuestos por la revolución tecnológica y al incremento de e integración de los mercados transnacionales, las nuevas formas comunicativas enfatizan el tema de la diferencia como elemento esencial de los nuevos desarrollos simbólicos" (pp. 166-167). Es de crucial importancia que los docentes tengamos en cuenta esta afirmación, pues los desarrollos simbólicos se refieren a las nuevas relaciones culturales que son esenciales para lograr una interacción e intercambio cultural a nivel mundial. Por esta razón, es importante diseñar actividades que no incluyan únicamente un contenido lingüístico o gramatical, sino intentar entrelazar competencias socio-lingüísticas y culturales apelando a nuevos lenguajes y nuevas formas de comunicación.

\footnotetext{
* Francés 4, Programa de Bachillerato Internacional, ITESM CCM. Semestre enero-mayo 2020.
} 


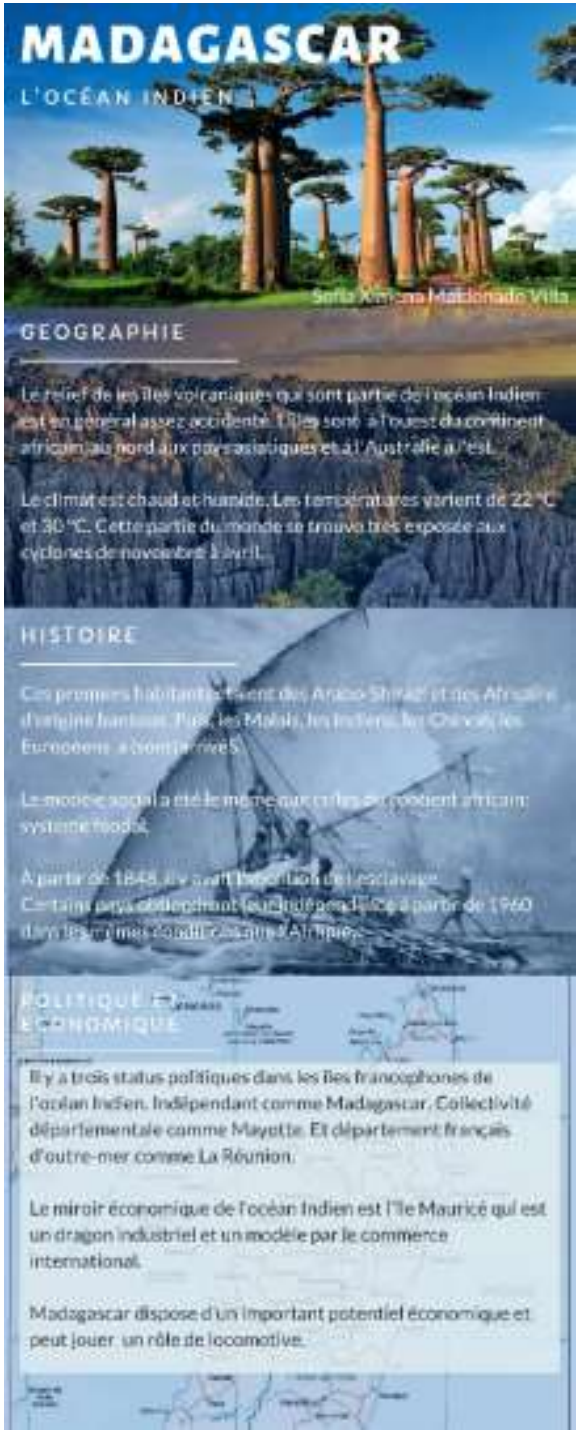

Figura 1. Copia de Infografía realizada en Canva.com, la cual sirvió como apoyo a una exposición oral de Storytelling sobre una leyenda de Canadá. La infografía sirvió para contextualizar la historia.

\section{Flipgrid: Registros orales y videos}

Flipgrid, https://admin.flipgrid.com, es una herramienta pedagógica que nos permite grabar videos. Sin embargo, el aporte de esta aplicación en clase no es sólo poder grabar un video, el cual puede hacerse desde un teléfono móvil, sino de mostrar la capacidad de espontaneidad de los estudiantes. Flipgrid graba desde la computadora o dispositivo un discurso en vivo, el cual muestra la expresividad del alumno, si éste está leyendo un guion o no y si el discurso se grabó por partes. Flipgrid permite conocer el avance de la producción oral de un aprendiente de manera remota y, al mismo tiempo, permite que otros miembros de esa comunidad observen los videos de otros compañeros e intercambien ideas, ya que la aplicación permite dar respuesta, retroalimentación e incluir comentarios. En el marco de la pandemia Covid-19, la aplicación de Flipgrid fue de gran utilidad para evaluar la expresión oral de mis alumnos, quienes prepararon videos sobre un tema específico. Para ejemplificar esto, me apoyaré en el grupo de francés antes mencionado, donde el proyecto de la Francofonía se extendió para convertirse en una unidad de aprendizaje. Esto quiere decir que el tema de la Francofonía abarcó más de una estructura gramatical, abarcando temas de vocabulario y nociones de cultura y civilización en países de habla francesa. A través de la actividad anterior, se desarrollaron competencias de comprensión escrita, búsqueda y organización de información específica y vinculación de vocabulario con símbolos e imágenes. Como actividad complementaria, los alumnos hicieron una exposición oral en Flipgrid, donde se explica el resultado obtenido de la actividad anterior; los estudiantes pueden narrar una historia $\mathrm{y}$ complementarla con pequeñas imágenes que apoyen su intervención (Figura 2).

Flipgrid permite a los profesores establecer rúbricas de evaluación dentro de cada grid y guiar al alumno con instrucciones y preguntas específicas. Es importante personalizar cada grid con imágenes referentes al tema para motivar a los alumnos y escribir la consigna detalladamente y con mucha claridad para facilitar las respuestas. Es necesario enfatizar que el aprendizaje virtual requiere dejar claros los conceptos, pero sobretodo las instrucciones a seguir. La evaluación y retroalimentación puede ser personal o grabarse como una respuesta.

Otra aportación de esta aplicación es el hecho de establecer una discusión virtual, favoreciendo así el intercambio de ideas y la producción oral en un contexto real ya que los grids tienen la opción de ser públicos o privados y pueden ser consultados como el ejemplo siguiente: https://admin.flipgrid.com/manage/grids/2819596. Esta liga está disponible para quienes forman parte de la comunidad Flipgrid.

Otro ejemplo que puedo mencionar es una actividad diseñada para un grupo de adultos de francés 5 (Nivel B1 MCRL), en la sede del Real Seminario de Minería de la Escuela Nacional de Lenguas, linguiística y traducción de la UNAM (ENALLT). Esta actividad requería grabar un video individual acerca de un viaje especial que hubiera aportado algún aprendizaje significativo o experiencia enriquecedora. Los alumnos contaron sus experiencias usando verbos en tiempos pasados (imparfait, passé composé, plus-que-parfait), adverbios de tiempo y lugar y conectores discursivos de causa $\mathrm{y}$ consecuencia. Este tipo de actividades nos permiten dar voz a nuestros estudiantes al tiempo que se desconstruyen los modelos de enseñanza tradicionales. Las actividades que incluyen contenidos multiculturales, que abordan el conocimiento de lugares y culturas desconocidas apelan a un modelo alternativo que dota de una perspectiva pluricultural a los aprendientes despegándose del modelo hegemónico y proporcionando herramientas que favorezcan el pensamiento crítico y valores de empatía y respeto. 


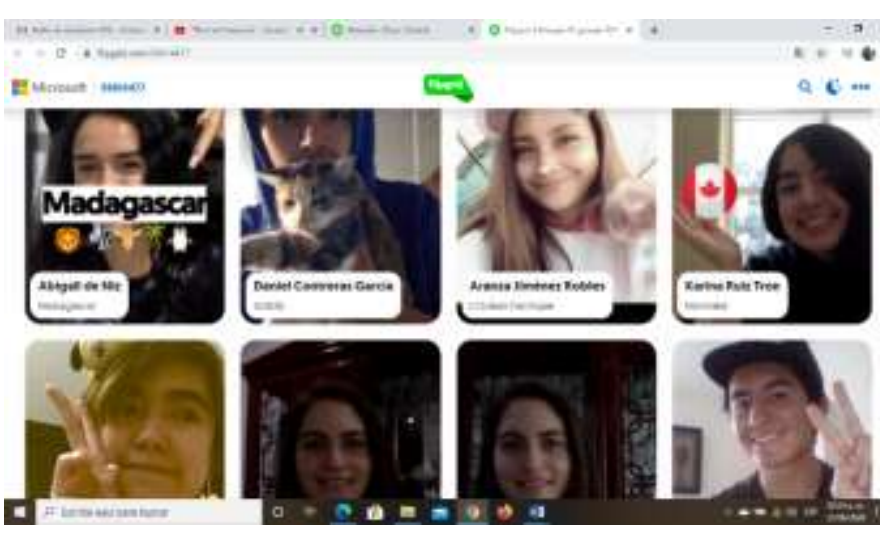

Figura 2. Portadas de los videos realizados por los estudiantes en Flipgrid. Se cita la liga de la plantilla, que es pública para los usuarios registrados en Flipgrid.com.

\section{Powtoon: Videos}

Powtoon es una aplicación que permite el uso de la creatividad y nuevos lenguajes; deja entera libertad al estudiante de crear un mensaje en una lengua extranjera; ha sido recomendada por las universidades de la Ivy League, productores de Hollywood y empresas transnacionales, con plantillas prediseñadas e imágenes y textos ya trazados que atraen e involucran diferentes apoyos educativos, además de ser avalado por Discovery Education y SchoolTube (ITESM, 2017, p. 12).

Mediante la grabación de videos, el alumno involucra diversas actividades de comprensión, reflexión y producción, oral, escrita y creativa. Esto ayuda incluso a la praxis interdisciplinaria del conocimiento adquirido dentro de situaciones que se vuelven reales al momento de compartirlas en una red social y hacerlas visibles en el espacio cibernético. Según Mabel Moraña "a medida que la cultura se globaliza y se trascienden las limitaciones impuestas por los nacionalismos y las compartimentaciones disciplinarias, se reafirma la necesidad de reformular las bases de un humanismo liberador, des-convencionalizado, descanonizado, que hable las lenguas múltiples de la oralidad, de la imagen y el sonido, de las formas masivas, populares, performativas y carnavalizadas de nuestro tiempo" (p. 209). A través de aplicaciones como Powtoon es posible poner en práctica esta interacción de lenguas múltiples, incluso el movimiento corporal y la expresión gestual. Al mismo tiempo, los alumnos conviven en un ambiente académico que pierde rigidez, pero no disminuye su nivel de exigencia. Para asegurarnos de esto, es necesario el uso de rúbricas coherentes con instrucciones claras que estén centradas en evaluar diferentes competencias y que no limiten la creatividad del estudiante.

Otras aplicaciones muy similares a Powtoon son Slidestory, creApp cuentos, Storyfy y Glogster. En niveles avanzados, estas aplicaciones permiten el desarrollo de proyectos interdisciplinarios o multidisciplinarios que aborden diversos objetos de estudio, como la Historia o las ciencias, contando cómo sucedió un acontecimiento relevante que cambió la historia de la humanidad o de un país. Asimismo, en estas aplicaciones, se pueden hacer caracterizaciones de personajes históricos o literarios, pequeñas obras de teatro o simplemente videos que argumenten algún punto de vista. Los proyectos pueden ser individuales o en equipos, fomentando así la colaboración académica. El proyecto de video funciona entonces como una actividad sumativa que comprende otras pequeñas actividades formativas, desde la búsqueda de información, diseño de imagen, guión, producción y presentación.

Es importante reafirmar que la elaboración de un video es un proceso que conlleva actividades previas que fomentan la lectura, la investigación y la convivencia. En la clase de francés 4, referida anteriormente, la aplicación Powtoon sirvió para realizar videos en relación con la estructura lingüística de la hypothèse, donde los alumnos imaginaron una historia alternativa sobre un hecho histórico relevante, vinculando así sus conocimientos de historia y literatura. El proyecto se llamó "L'histoire non-officielle" y los alumnos, reunidos en equipos de 4 o 5 personas, presentaron una hipótesis sobre temas como el descubrimiento de América, la conquista de México, artistas como Michael Jackson o la supuesta supervivencia de Anastasia Romanov (Figura 3).

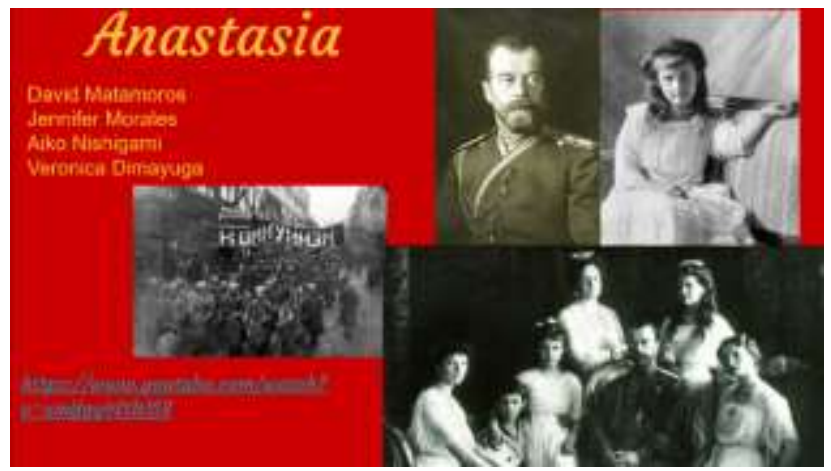

Figura 3. Portada del video sobre "l'histoire non-officielle" de Anastasia Romanov

En sus exposiciones orales, los estudiantes contaron una historia alterna a la oficial, imaginando un final diferente; por ejemplo, si Hernán Cortés hubiera perdido la guerra contra los aztecas (Figura 4). La consigna era describir el contexto utilizando tiempos pasados (passé composélimparfait) y utilizar al menos 5 frases hipotéticas con los tiempos verbales imparfait y conditionnel. Al mismo tiempo que se revisaron los tiempos pasados, se incluía un nuevo tema y se vinculaban dentro de la narración. El resultado fue muy satisfactorio, ya que los alumnos encontraron la actividad muy divertida, imaginando situaciones extrañas y a veces incluso cómicas.

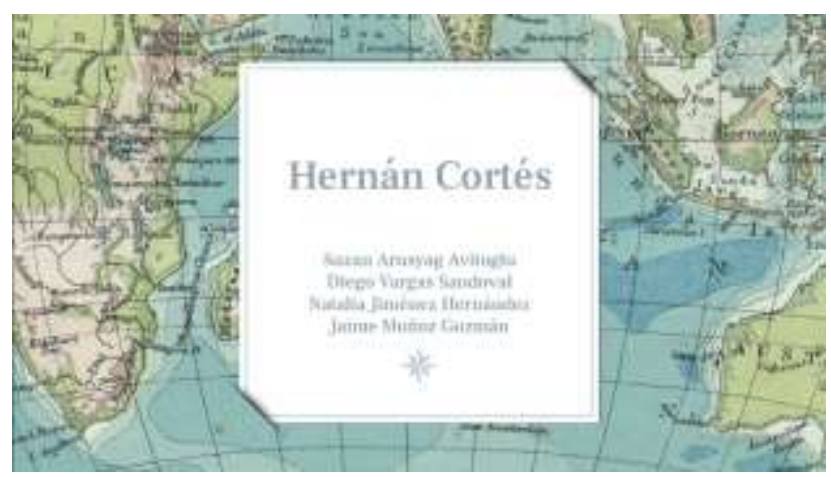

Figura 4. Portada del video sobre "l'histoire non-officielle" de Hernán Cortés 


\section{CONCLUSIONES}

Es necesario puntualizar que las actividades mencionadas fueron llevadas a cabo en grupos de aprendizaje de FLE en niveles medio-superior y superior, en el Instituto Tecnológico de Estudios Superiores de Monterrey, CCM y en la Escuela Nacional de Lenguas, Literatura y Traducción (ENALLTUNAM). Los resultados de este proyecto sirven como base al presente artículo, así como fueron aportaciones y conclusiones finales del curso Estrategias educativas para el Profesor Tec21, impartido en la misma sede del ITESM durante el semestre enero-mayo 2020.

Con este proyecto se pretende enfatizar la necesidad de poner en relación la tecnología y las humanidades, ya que el contacto humano es fundamental para que un individuo desarrolle sus capacidades con plenitud y pueda desenvolverse en su entorno contribuyendo a un bienestar común. Si bien las ciencias sociales y las artes han tardado un poco más en adaptarse a los nuevos lenguajes, es momento de plantear, discutir y crear nuevas estrategias de enseñanza-aprendizaje que permitan fomentar la cultura dentro del ciberespacio y las nuevas plataformas. Suscribo la afirmación de Mabel Moraña (2014), "El humanismo, primariamente dominio de las letras y la filosofía y campo de reflexión sobre las manifestaciones de lo humano, se abre a la experiencia de lo post-humano, donde la máquina y los mundos virtuales abren nuevas avenidas y desafíos a la razón y a la sensibilidad" (p. 205), pero hago hincapié en que la tecnología no es un remplazo de la actividad académica. Las herramientas que la tecnología proporciona enriquecen el aprendizaje, pero no quiere decir que se omite la estructura gramatical ni sintáctica. Los ejemplos aquí presentados funcionan como actividades de sistematización y sincronización de conocimientos previos, pero no pueden sustituir la estructura lingüística u omitir la explicación de la misma.

Una de las mayores ventajas que presenta la estrategia del Storytelling es la posibilidad de crear un contexto real de intercambio de ideas fuera de la simulación, al abrir un panorama cibernético que puede compartirse con otras comunidades académicas en plataformas educativas y, en el caso de niveles superiores, en redes sociales. Esto favorece un intercambio real, incluso en contextos globales gracias a redes de comunicación eficientes. Sin embargo, es preciso hacer notar a los estudiantes que si bien la internet presenta una sobrecarga de información, es crucial aprender a discernir la información útil y pertinente para poder lograr una comprensión de su objeto de investigación.

El rol del profesor no solo consiste en contar una historia o moderar la narración de historias por parte de los alumnos, sino también de dirigir el diseño y la creación de proyectos estructurados con objetivos claros. De este modo, la clase se vuelve dinámica y más atractiva para los alumnos, aumenta la participación y mejora la producción oral.

Si bien la tecnología abre nuevos caminos, presenta a su vez, riesgos considerables, como la falta de manejo de aplicaciones tanto por parte de alumnos como maestros. No obstante, esta dificultad puede solucionarse abriendo nuevos caminos didácticos con los enseñantes. Si empezamos a compartir nuestras experiencias docentes y crear redes de trabajo y de investigación, el avance será más notorio. Cabe señalar que la experimentación es inevitable y estamos expuestos a errores, aunque una de las estrategias que pueden volver esta práctica más fácil es diseñar previamente el proyecto a realizar dejando claro el objetivo de aprendizaje y valiéndose de un tema que sea interesante para la mayoría.

Otra reflexión importante que debemos tener en cuenta es que el aprendizaje para ser significativo, debe ser útil y duradero. No basta la memorización si ésta no implica la colaboración activa del individuo en su entorno con la finalidad de mejorarlo. El conocimiento implica compromiso frente al Otro y frente a nuestro entorno. Como afirmaban Wiggings y McTigh (2005), "stimulate thought, provoke inquiry and to spark more questions, including thoughtful student questions", (p. 106). Las historias hacen surgir preguntas, comentarios y opiniones que enriquecen el panorama de interpretación y análisis.

En suma, la propuesta de este trabajo es sugerir modelos de planeación educativa que ayuden a desmitificar el aprendizaje rígido, a construir aprendizajes integrales que proporcionen herramientas para enfrentar la nueva realidad dentro y fuera del ciberespacio y, a su vez, que enfaticen la importancia de la vida y las relaciones humanas por encima de los recursos materiales. Es preciso que ambos, estudiantes y profesores nos comprometamos en el diseño de una educación que privilegie la curiosidad y el placer por el conocimiento; éste último encaminado a la contribución de un mundo más solidario y con equidad entre todas las personas sin importar su condición. El conocimiento del Otro y el desarrollo de la empatía son, sin duda, tan esenciales como el conocimiento teórico. El Storytelling permite la convergencia de ambos tipos de aprendizaje y fomentar, al mismo tiempo, el placer por la literatura y las artes.

\section{REFERENCIAS}

[1] Alderman, N. (2015). "The first great works of digital literature are already being written", en The Guardian [Weblog post]. Recuperado de https://www.theguardian.com/technology/2015/oct/13/video-games-digit al-storytelling-naomi-alderman

[2] Bauman, Z. (2011). La cultura en el mundo de la modernidad líquida. México: FCE.

[3] Bauman, Z (2008). Los retos de la educación en la modernidad líquida. Barcelona: Gedisa.

[4] Cooper, J. D. (1990). Como Mejorar la Comprensión Lectora. Madrid: Aprendizaje Visor-MEC.

[5] Díaz Barriga, F. (1999). Estrategias para un aprendizaje significativo. México: McGraw Hill.

[6] Gil de la Piedra, C. (2014). La nueva estructuración del programa de FLE dentro del Bachillerato Internacional (BI). México: Facultad de Filosofía y letras-UNAM. Recuperado de http://132.248.9.195/ptd2015/anteriores/filosofia/0723953/Index.html

[7] ITESM (2017). Storytelling. EduTrends. Obervatorio de la Inovación educativa. Instituto Tecnológico de Estudios Superiores de Monterrey.

\footnotetext{
* Estimular el pensamiento provoca indagación y el brote de nuevas preguntas, incluyendo preguntas reflexivas de los alumnos (Traducción mía).
} 
[8] Jenkis, H. (2006) How Transmedia Storytelling Begat Transmedia Planning... parte 1 [Weblog post]. Recuperado de http://henryjenkins.org/2006/12/how_transmedia_storytelling_be.html.

[9] Moraña, M. (2014). Inscripciones críticas. Ensayos sobre cultura latinoamericana. Santiago: Cuarto propio.

[10] Porcher, L. y Groux, D. (2013). Le storytelling: Un angle neuf pour aborder les disciplines? Francia: L'Harmattan.

[11] Turner, J.M. (1998). « Digital image access \& retrieval » en Journal of the American Society for Information Science. Recuperado de: https://doi.org/10.1002/(SICI)1097-4571(199806)49:8<766::AIDASI11>3.0.CO;2-N

[12] Valéry, P. (2011). Le bilan de l'intelligence. Paris: Allia.

[13] Wiggings, G. y McTigh, J. (2005). Understanding by design. Alexandria, USA: ASCD. 